Check for updates

Cite this: Chem. Sci., 2019, 10, 4339

๑ All publication charges for this article have been paid for by the Royal Society of Chemistry

Received 16th December 2018 Accepted 12th March 2019

DOI: $10.1039 / \mathrm{c} 8 \mathrm{sc} 05612 \mathrm{a}$

rsc.li/chemical-science

\section{A versatile catalyst system for enantioselective synthesis of 2-substituted 1,4-benzodioxanes $\dagger$}

\author{
Eugene Chong, (D) *a Bo Qu, (D) *a Yongda Zhang, (D) *a Zachary P. Cannone, ${ }^{a}$ \\ Joyce C. Leung, ${ }^{a}$ Sergei Tcyrulnikov, ${ }^{b}$ Khoa D. Nguyen, (D) a Nizar Haddad, ${ }^{a}$ \\ Soumik Biswas, ${ }^{a}$ Xiaowen Hou, ${ }^{a}$ Katarzyna Kaczanowska, ${ }^{c}$ Michat Chwalba, ${ }^{c}$ \\ Andrzej Tracz, ${ }^{c}$ Stefan Czarnocki, ${ }^{c}$ Jinhua J. Song, ${ }^{a}$ Marisa C. Kozlowski (D) *b \\ and Chris H. Senanayake ${ }^{\text {ad }}$
}

\begin{abstract}
We report the synthesis of enantiomerically enriched 1,4-benzodioxanes containing alkyl, aryl, heteroaryl, and/or carbonyl substituents at the 2-position. The starting 1,4-benzodioxines were readily synthesized via ring closing metathesis using an efficient nitro-Grela catalyst at ppm levels. Excellent enantioselectivities of up to 99:1 er were obtained by using the versatile catalyst system $\left[\mid \mathrm{r}(\mathrm{cod}) \mathrm{Cl}_{2} /\right.$ BIDIME-dimer in the asymmetric hydrogenation of 2-substituted 1,4-benzodioxines. Furthermore, DFT calculations reveal that the selectivity of the process is controlled by the protonation step; and coordinating groups on the substrate may alter the interaction with the catalyst, resulting in a change in the facial selectivity.
\end{abstract}

Enantiomerically pure 1,4-benzodioxane derivatives are widely found in biologically active compounds. ${ }^{1}$ They possess interesting biological activities such as $\alpha$-adrenergic blocking, ${ }^{2}$ antigastric, ${ }^{3}$ spasmolytic, ${ }^{4}$ antipsychotic, ${ }^{5}$ anxiolytic, ${ }^{6}$ and hepatoprotective properties ${ }^{7}$ (see Fig. 1 for selected examples). As

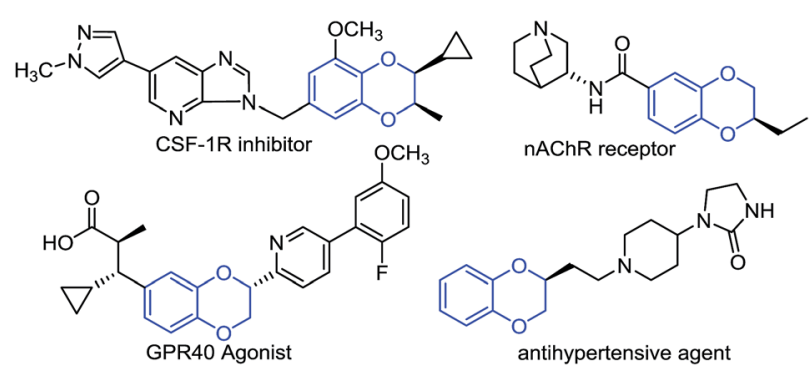

Fig. 1 Examples of chiral 1,4-benzodioxane containing molecules.

${ }^{a}$ Chemical Development, Boehringer Ingelheim Pharmaceuticals, Inc., 900 Ridgebury Road, Ridgefield, CT 06877, USA. E-mail: eugene.chong@boehringer-ingelheim.com; bo.qu@boehringer-ingelheim.com; yongda.zhang@boehringer-ingelheim.com

${ }^{b}$ Department of Chemistry, University of Pennsylvania Philadelphia, PA 19104, USA. E-mail:marisa@sas.upenn.edu

'Apeiron Synthesis S.A. Wroclaw Technology Park ul, Duńska 9, 54-427 Wrocław, Poland

${ }^{d}$ Astatech BioPharmaceutical Corporation, 488 Kelin West Road, Wenjiang Dist., Chengdu, Sichuan 611130, P. R. China

$\dagger$ Electronic supplementary information (ESI) available. See DOI: $10.1039 / \operatorname{cosc} 05612 \mathrm{a}$ a result, their enantioselective syntheses have attracted great attention in the past decades.

Whereas early efforts to synthesize enantiomerically enriched 2,3-dihydro-1,4-benzodioxine containing compounds focused primarily on the use of chiral building blocks ${ }^{8}$ or enzymatic kinetic resolution of carboxylic acids and derivatives, ${ }^{9}$ recent investigations have increasingly focused on exploiting chiral catalysts. Highly enantioselective processes have been developed including Pd-catalyzed asymmetric intramolecular $O$-arylative coupling reactions ${ }^{10}$ and asymmetric intramolecular alkene aryloxyarylation reactions. ${ }^{11}$ Furthermore, direct asymmetric hydrogenation of the 1,4-benzodioxine derivatives has been realized recently via Ir-catalyzed reduction of 2-aryl-1,4-benzodioxines ${ }^{12}$ and Rh-catalyzed reduction of 2carboxyl-1,4-benzodioxines, ${ }^{13}$ each of which has limited substrate scope. We aimed to discover a catalyst system that is effective and enantioselective for valuable alkyl and heteroaryl substituted products. Herein, we report a versatile $[\operatorname{Ir}(\operatorname{cod}) \mathrm{Cl}]_{2} /$ BIDIME-dimer catalyst system for enantioselective synthesis of a wide range of 2-substituted 1,4-benzodioxanes containing polar directing carbonyl groups as well as largely unfunctionalized groups including alkyls, aryls and heteroaryls. Furthermore, a mechanistic rationale for the reversal of facial selectivity between different substrates is provided based on DFT calculations.

We commenced our studies by preparing the requisite starting materials, 2-substituted 1,4-benzodioxines. We proposed to construct the key 1,4-benzodioxines fragment using a ring closing metathesis (RCM) strategy after alkylation of catechol derivatives (Scheme 1). RCM on substrates containing 
vinylic ethers is known to be problematic. ${ }^{\mathbf{1 4}}$ High catalyst loadings of Grubb's second-generation catalyst (5-8 mol\%) were reported for the synthesis of 1,4-benzodioxines, ${ }^{15}$ which hindered the practicality of this otherwise powerful transformation. Furthermore, any coordinating group on the substrate would negatively impact the efficiency of the metathesis reaction. In searching for an effective catalyst, we hypothesized that Grela's nitro-aryl RCM catalysts would facilitate the initial metathesis event due to the labile and less Lewis basic nature of the isopropoxy donor. Gratifyingly, the bismesityl-substituted dichloro nitro-Grela catalyst is very reactive even for ortho-methyl ester substrate $\mathbf{3 b}$. As a result, compounds $\mathbf{4 a}$ and $\mathbf{4 b}$ were prepared using 150 or $300 \mathrm{ppm}$ of the catalyst in $>80 \%$ yields (Scheme 1 ).

With a highly efficient synthesis of the 2-substituted 1,4benzodioxines in hand, enantioselective reduction was tested. The initial focus was on the asymmetric hydrogenation of 2cyclopropyl-substituted substrate 5a (Table 1). Given that a general, highly enantioselective method for 2-alkylsubstituted 1,4-benzodioxanes has not been reported to date, we theorized that the small size of the cyclopropyl substituent would be a good test case for this purpose. More than 20 commercially available bidentate phosphine ligands were screened $^{\mathbf{1 6}}$ (representative examples are shown in Table 1, entries 1-8); however, all of the screened ligands provided moderate enantioselectivities ( $<90: 10$ er), and the reaction did not reach full conversion even with addition of acetic acid $(\mathrm{AcOH})$, which was reported to increase the reactivity of the catalyst for iridium-catalyzed hydrogenation. ${ }^{17}$ We hypothesized that the chiral bis-dihydrobenzooxaphosphole (BIBOP) type ligands (L1-L5) could be used to advantage for this transformation, as they have the potential to provide a deep chiral pocket as well as steric tunability for enantioinduction. ${ }^{19}$ By increasing the size of the substituent on the BIBOP ligands from hydrogen to aryl, a general increase in enantioselectivity and conversion was observed (Table 1, entries 9-13). Notably, 9anthracenyl-substituted ligand L4 (WingPhos) provided 95:5 er; and 2,6-dimethoxyphenyl-substituted ligand L5 (BIDIMEdimer) provided the highest enantioselectivity (97:3 er). Importantly, side products from cyclopropyl ring opening or ester hydrolysis were not observed under the reaction conditions and product $6 \mathbf{6}$ was isolated in 98\% yield using the BIDIME-dimer ligand.

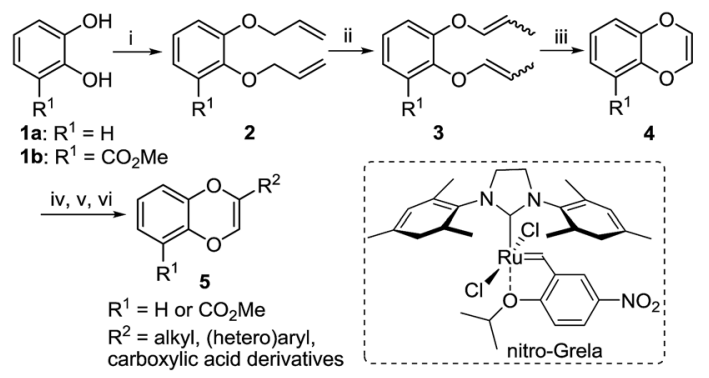

i) allyl bromide, $\mathrm{K}_{2} \mathrm{CO}_{3}$, MeCN; ii) $\mathrm{RuClH}(\mathrm{CO})\left(\mathrm{PPh}_{3}\right)_{3}(1.0-3.0 \mathrm{~mol} \%$ ); iii) NitroGrela (150-300 ppm); iv) NBS; v) base; vi) $\mathrm{Pd}(\mathrm{OAc})_{2} / \mathrm{L} /$ boronic acids or Grignards

Scheme 1 Synthesis of 1,4-benzodioxines.
Table 1 Ligand screening of Ir-catalyzed asymmetric hydrogenation of cyclopropyl-substituted 1,4-benzodioxine $5 a^{a}$

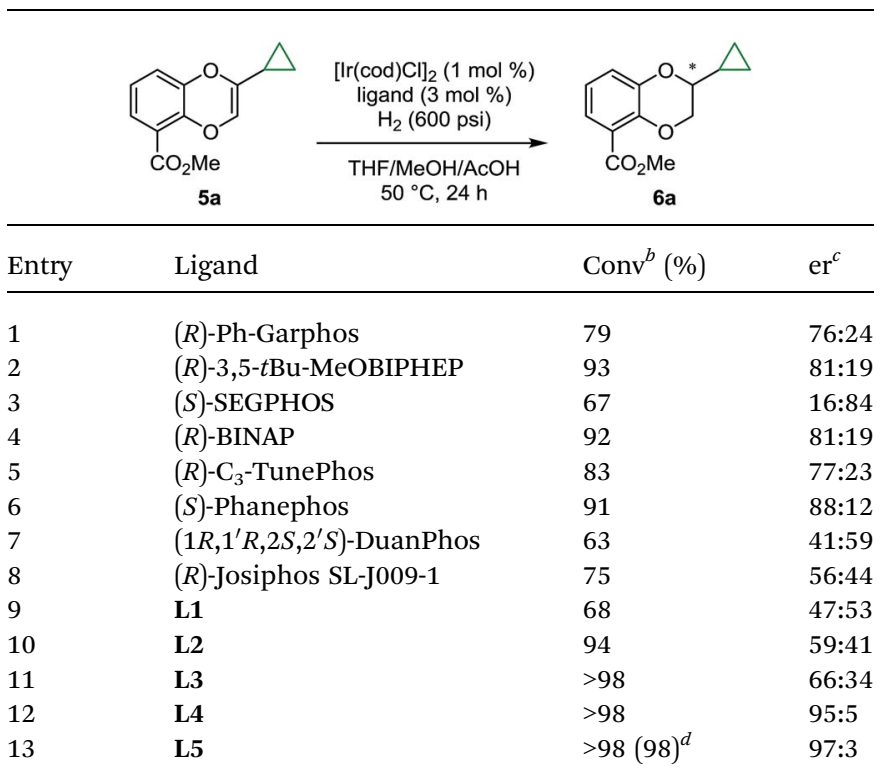

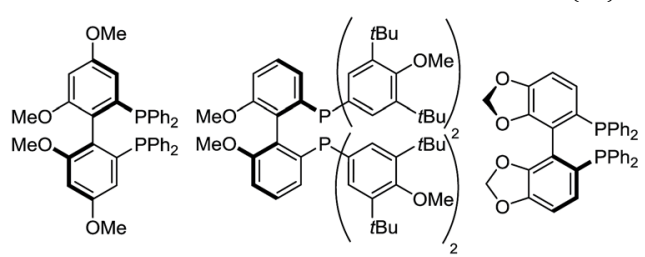

$\begin{array}{lll}(R)-P h-G a r p h o s & (R)-3,5-t-\mathrm{Bu}-4-\mathrm{MeO}-\mathrm{MeOBIPHEP} & \text { (S)-SEGPHOS }\end{array}$

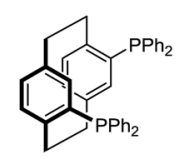

(S)-Phanephos

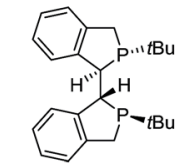

$\left(1 R, 1^{\prime} R, 2 S, 2^{\prime} S\right)$-DuanPhos $(R)$-SL-J009-1

(R)-BINAP
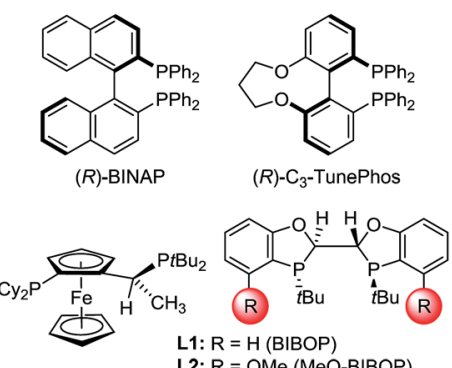

2: $\mathrm{R}=\mathrm{OMe}(\mathrm{MeO}-\mathrm{BIBOP})$

L3: $\mathrm{R}=\mathrm{Ph}(\mathrm{Ph}-\mathrm{BIBOP})$

4: $R=$ 9-anthracenyl (WingPhos)

L5: $\mathrm{R}=2,6-(\mathrm{MeO})_{2} \mathrm{C}_{6} \mathrm{H}_{3}$ (BIDIME-dimer)
${ }^{a}$ Reaction conditions: $:^{18} 5 \mathrm{a}(0.1 \mathrm{mmol}),[\operatorname{Ir}(\operatorname{cod}) \mathrm{Cl}]_{2}(0.001 \mathrm{mmol})$, ligand $(0.003 \mathrm{mmol})$, THF $(0.2 \mathrm{~mL}), \mathrm{MeOH}(0.2 \mathrm{~mL}), \mathrm{AcOH}(4 \mathrm{mmol}), \mathrm{H}_{2}(600$ psi), $50{ }^{\circ} \mathrm{C}$ for $24 \mathrm{~h}$. ${ }^{b}$ Conversion was determined by HPLC. ${ }^{c}$ Enantiomeric ratio was determined by chiral SFC. ${ }^{d}$ Isolated yield.

Having identified BIDIME-dimer as the optimal ligand, other 2-alkyl-substituted 1,4-benzodioxines were examined in the Ir-catalyzed asymmetric hydrogenation reaction (Scheme 2). The cyclopropyl analogue without the methyl ester substituent at the 5-position was hydrogenated to afford $\mathbf{6 b}$ with comparable enantioselectivity (94:6 er). Other cycloalkyl substituents ranging from 4- to 7-membered-rings also performed well in the reaction to give the corresponding 1,4benzodioxanes (6c-6e) with very good enantioselectivities. Additionally, 2-aryl-substituted 1,4-benzodioxanes $\mathbf{6 f}$ and $\mathbf{6 g}$ were synthesized with excellent enantioselectivities of 98:2 er and >99:1 er, respectively. The synthesis of 6 f $(98: 2 \mathrm{er})$ is 

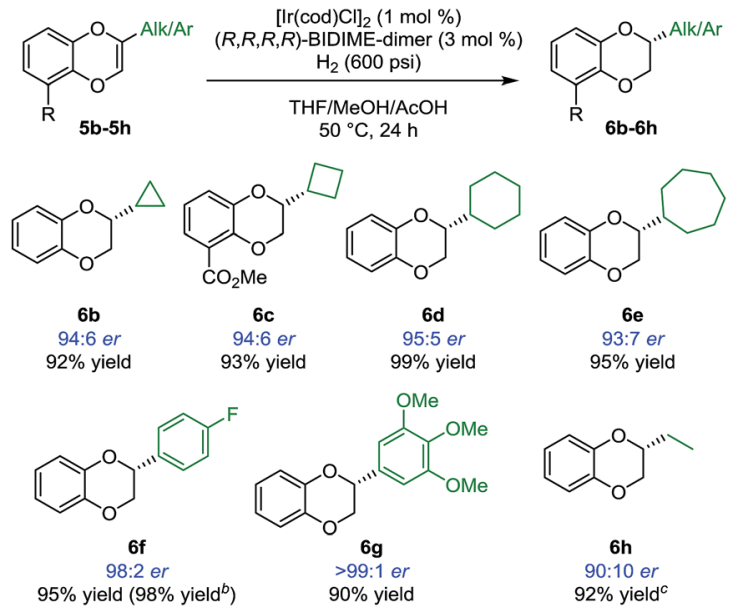

Scheme 2 Asymmetric hydrogenation of 2-alkyl and 2-arylsubstituted 1,4-benzodioxines ${ }^{a}$. ${ }^{a}$ Reaction conditions: $5(0.2 \mathrm{mmol})$, [lre (cod) $\mathrm{Cl}_{2}(0.002 \mathrm{mmol}),(R, R, R, R)$-BIDIME-dimer L5 $(0.006 \mathrm{mmol})$, $\operatorname{THF}(0.3 \mathrm{~mL}), \mathrm{MeOH}(0.3 \mathrm{~mL}), \mathrm{AcOH}\left(8 \mathrm{mmol}, 40\right.$ equiv.), $\mathrm{H}_{2}(600 \mathrm{psi})$, $50{ }^{\circ} \mathrm{C}$ for $24 \mathrm{~h}$. Isolated yield. Enantiomeric ratio was determined by chiral SFC or HPLC. ${ }^{b} 5 \mathrm{f}(5.0 \mathrm{mmol}, 1.14 \mathrm{~g})$, $[\mathrm{rr}(\mathrm{cod}) \mathrm{Cl}]_{2}(0.005 \mathrm{mmol}), \mathrm{L} 5$ (0.015 mmol), THF ( $6 \mathrm{~mL}), \mathrm{MeOH}(6 \mathrm{~mL}), \mathrm{AcOH}(150 \mathrm{mmol}, 30$ equiv.), $\mathrm{H}_{2}\left(600\right.$ psi), $70{ }^{\circ} \mathrm{C}$ for 24 h. ${ }^{\mathrm{C}} 25^{\circ} \mathrm{C}$.

a significant improvement over the recently reported IrBARF/ In-BiphPHOX system (91.5:8.5 er) (BARF = tetrakis(3,5bis(trifluoromethyl) phenyl)borate). ${ }^{12}$ Furthermore, gram scale reduction of $\mathbf{5} \mathbf{f}$ was demonstrated with $0.1 \mathrm{~mol} \%$ [Ir(cod) $\mathrm{Cl}]_{2}$. Quantitative yield (98\%) and the same enantiomeric ratio (98:2) were obtained. Even for the challenging ethyl substituted $\mathbf{6 h}$, much higher enantioselectivity was obtained (90:10 er $v s .74: 26 \mathrm{er}^{12}$ ).

In most reductions of largely unfunctionalized alkenes, noncoordinating anions such as BARF are needed to enhance the coordination of the iridium catalyst to the substrate. As a result, nitrogen-containing heterocycles are generally not compatible with Ir-BARF catalyst systems. ${ }^{12,20}$ With the excellent enantioselectivities observed in our initial studies, we envisioned that $[\operatorname{Ir}(\operatorname{cod}) \mathrm{Cl}]_{2} /$ BIDIME-dimer catalyst system would allow selective alkene coordination $v s$. heterocycle coordination due to the lower Lewis acidity of the iridium and the deep binding pocket. If so, a number of products containing heterocyclic substituents of pharmaceutical relevance would be accessible in an expeditious manner. Indeed, a variety of benzodioxines with heteroaryl substituents were reduced under the reaction conditions (Scheme 3). 1,3-Benzodioxoles $\mathbf{6 i}$ and $\mathbf{6 j}$ were obtained in 98:2 er and 94:6 er, respectively. Benzothiophene $\mathbf{6} \mathbf{k}$ was generated in 99:1 er. Excellent enantioselectivities (>99:1 er) were obtained with more sterically demanding dibenzofuran $(\mathbf{6 1})$ and dibenzothiophene $(\mathbf{6 m})$ substituents. Importantly, many 1,4-benzodioxanes containing $N$-heterocyclic substituents at the 2position (6n-6x) can be prepared with consistently excellent enantioselectivities ( $\geq 98: 2 \mathrm{er}$ ). These cases include heterocycles containing two adjacent heteroatoms such as pyrazole (6n), indazole (6o), and isoxazole (6p). Furthermore, a variety of substrates containing pyridine functionality $(\mathbf{5 q}-\mathbf{5 v})$ underwent
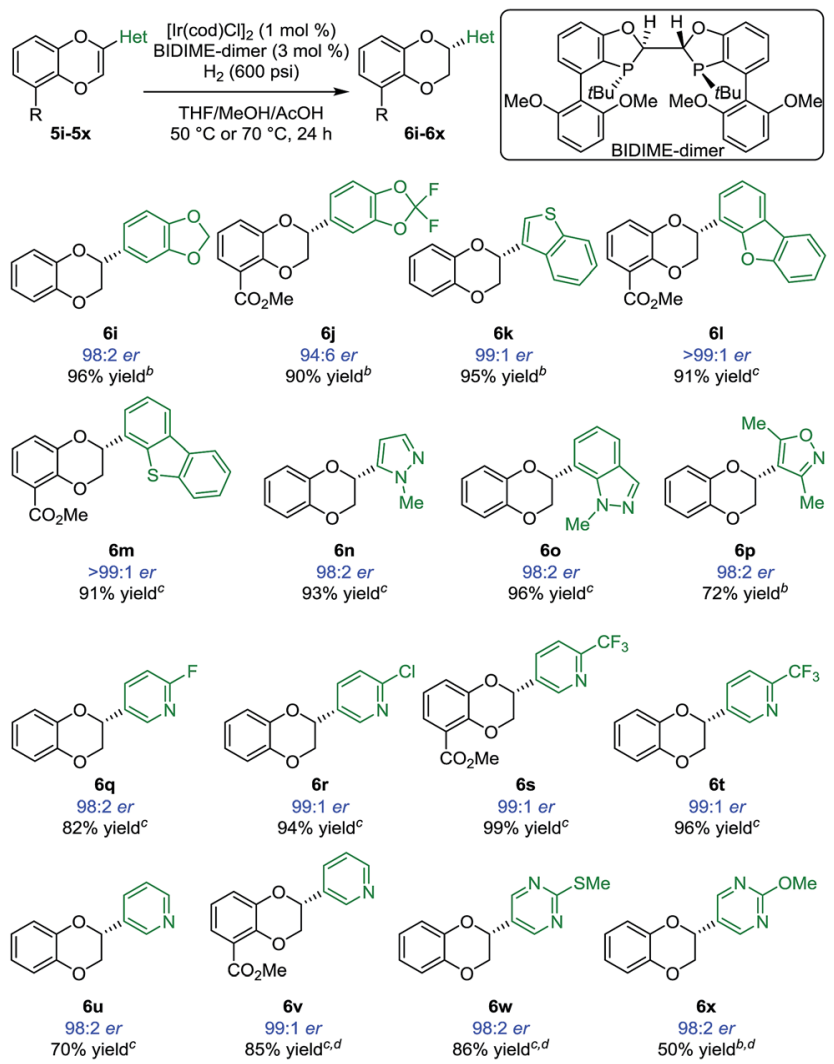

Scheme 3 Scope of Ir-catalyzed asymmetric hydrogenation of 2heterocycle-substituted 1,4-benzodioxines ${ }^{a}$. ${ }^{a}$ Unless noted, standard reaction conditions: substrate $5(0.2 \mathrm{mmol}),\left[\operatorname{lr}(\mathrm{cod}) \mathrm{Cl}_{2}(0.002 \mathrm{mmol})\right.$, $(R, R, R, R)$-BIDIME-dimer L5 $(0.006 \mathrm{mmol}), \operatorname{THF}(0.3 \mathrm{~mL}), \mathrm{MeOH}(0.3$ $\mathrm{mL}), \mathrm{AcOH}(8 \mathrm{mmol}), \mathrm{H}_{2}(600 \mathrm{psi}), 50$ or $70{ }^{\circ} \mathrm{C}$ for $24 \mathrm{~h}$. Isolated yield. Enantiomeric ratio was determined by chiral SFC or HPLC. ${ }^{b} 50{ }^{\circ} \mathrm{C}$. ${ }^{c} 70{ }^{\circ} \mathrm{C} .{ }^{d}\left[\mathrm{Ir}(\mathrm{cod}) \mathrm{Cl}_{2}\right.$ (2 mol\%), BIDIME-dimer L5 (6 mol\%).

asymmetric hydrogenation successfully. Substrates containing challenging pyrimidine derivatives ( $\mathbf{6} \mathbf{w}$ and $\mathbf{6 x}$ ) also performed well in the reaction.

In addition to heterocyclic substituents, the $[\operatorname{Ir}(\operatorname{cod}) \mathrm{Cl}]_{2} /$ BIDIME-dimer catalyst system is able to furnish chiral 1,4benzodioxanes containing polar coordinating carbonyl derivatives $^{21}$ (Scheme 4). Excellent enantioselectivity of $>99: 1$ er was obtained for the double methyl ester containing compound $\mathbf{6 y}$. 2-Methyl ester containing substrate $6 \mathbf{z}$ was obtained in 95:5 er. A variety of amide derivatives incorporating pyrrolidine 6aa (93:7 er), morpholine 6ab (98:2 er), piperidine 6ac (97:3 er), piperazine 6ad (98:2 er), and tetrahydroisoquinoline 6ae (97:3 er) were also generated with high enantioselectivity. Overall, these results establish the broad applicability of the IrCl/BIDIMEdimer catalyst system for enantioselective synthesis of 2substituted 1,4-benzodioxanes with a range of both coordinating and non-coordinating substituents. Interestingly, the opposite chirality was observed when a polar carbonyl group was incorporated at the 2-position. To understand this unexpected result and gain insight into mechanism of stereoinduction, we initiated a computational study of this transformation. 


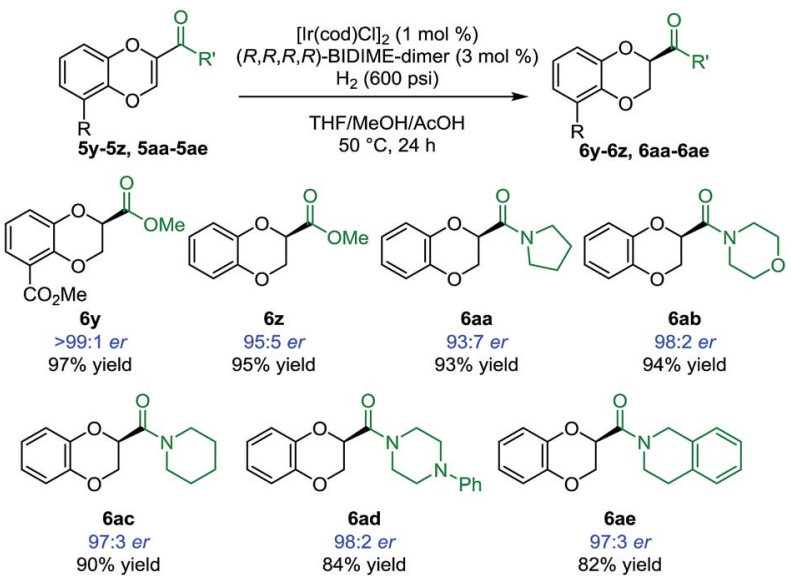

Scheme 4 Scope of Ir-catalyzed asymmetric hydrogenation of 1,4benzodioxines ${ }^{a}$. ${ }^{a}$ Reaction conditions: 5 (0.2 moll), $\left[\operatorname{lr}(\mathrm{cod}) \mathrm{Cl}_{2}(0.002\right.$ $\mathrm{mmol}),(R, R, R, R)$-BIDIME-dimer $\mathrm{L} 5(0.006 \mathrm{mmol}), \mathrm{THF}(0.3 \mathrm{~mL}), \mathrm{MeOH}$ $(0.3 \mathrm{~mL}), \mathrm{AcOH}(8 \mathrm{mmol}), \mathrm{H}_{2}(600 \mathrm{psi}), 50{ }^{\circ} \mathrm{C}$ for $24 \mathrm{~h}$. Isolated yield. Enantiomeric ratio was determined by chiral SFC or HPLC.

Based on the previous studies of related Ir-catalyzed hydrogenations, reduction was expected to occur by sequential protonation-hydride transfer mechanism (Fig. 2). ${ }^{22}$

In such a mechanism, protonation or hydride transfer can be enantiodetermining. Calculations of this system indicate that the energy of the separated ion pair is much higher than that of the protonation transition state (by $\sim 25 \mathrm{kcal} \mathrm{mol}^{-1}$ ) or the subsequent hydride transfer transition state. Since transfer of the iridium hydride to the opposite face via the separated ion pair is not favorable energetically, the calculations support the Ir catalyst establishing a facial preference during the protonation stage. To understand the origin of this facile preference and the enantioselectivity observed, we further analyzed the protonation step computationally. We found that protonation of both alkyl and carboxymethyl substituted benzodioxines proceeds as a Markovnikov process (C2 protonation on Fig. 2. See ESI $\dagger$ for details). We confirmed this regioselectivity for the

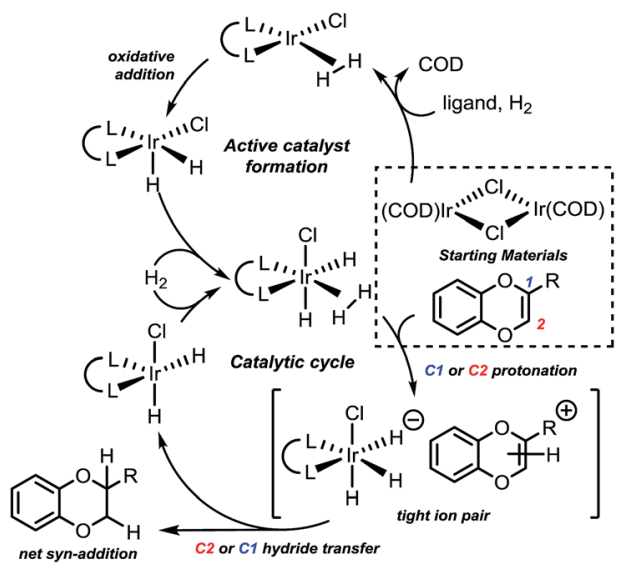

Fig. 2 Proposed hydrogenation mechanism. See ESI† for the computational analysis of the active catalyst formation. Computational study performed for $\mathrm{R}=\mathrm{Me}$ and $\mathrm{R}=\mathrm{CO}_{2} \mathrm{Me}$. reaction on both faces of the benzodioxine. This feature of the mechanism allows us to use the same model for both electronpoor and electron-rich R substituents.

As the reaction takes place in a polar medium, ionization of or loss of dihydrogen from the Ir complexes is highly likely ${ }^{23}$ (Fig. 3). For the non-coordinating substrates, we propose protonation via a 'mode A' mechanism, where substrate reacts with a neutral or cationic Ir complex. Both neutral and cationic mode A mechanisms provide very similar ligand-substrate interactions that determine the stereochemical outcome of the reaction, allowing us to consider only one of these mechanisms in our study.

For the coordinating substrate we envision an intramolecular process where the substrate coordinates the metal center prior to protonation (mode B). Such an arrangement will cause the subsequent reaction with dihydrogen to be more entropically favorable than in mode $\mathrm{A}$. We propose that different arrangements of the mode A and mode B transition states alter the selectivity determining ligand-substrate interactions, thereby affecting the facial preference of the protonation. To test this hypothesis, the reactions of methyl and carboxymethyl substituted benzodioxines were analyzed. Computational analysis of the mode A-protonation of the methyl substrate indicated that reaction takes place preferentially on the face A of the starting material (see Fig. 4).

In contrast, the protonation of the methoxycarbonyl substituted benzodioxine via mode B favors proton delivery to face $\mathrm{B}$, resulting in the opposite selectivity (Fig. 5).

The selectivity of the methyl substrate appears to be dictated by an unfavorable steric interaction between the substrate and the aryl portion of the ligand (Fig. 6, mode A). The computationally predicted selectivity is in good agreement with experimental results (Fig. 4, computed 80:20 vs. experimental 90:10). In contrast, control of the stereoselectivity with the methyl ester is provided by the stabilizing electronic interactions (Fig. 6, mode B). Computationally predicted values for enantiomeric ratio of this substrate are also in very good agreement with

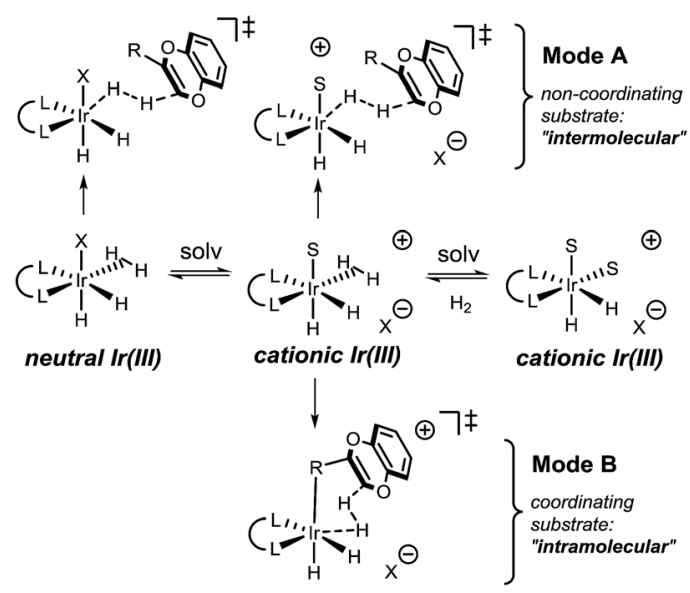

Fig. 3 Possible solvation equilibrium and proposed protonation transition states for coordinating and non-coordinating substrates. 


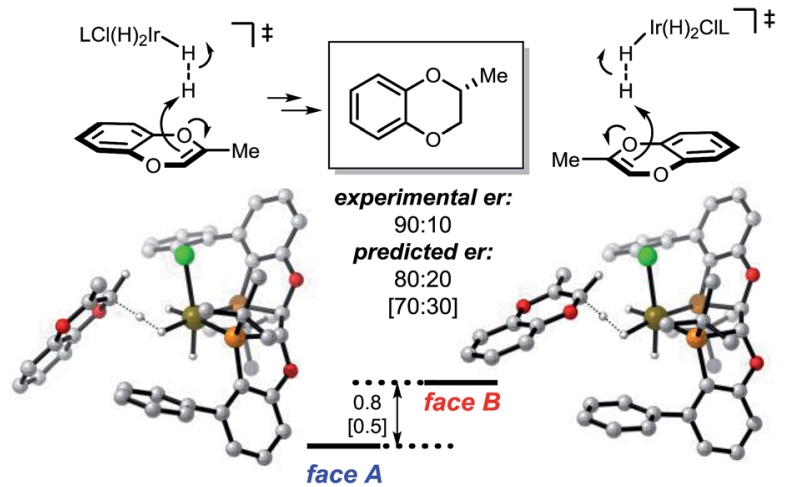

Fig. 4 Energetics of the mode A protonation of the Me-substituted benzodioxine. Selectivity-determining conformations are shown. Free energy and enthalpy (in brackets) gaps are calculated using PBE-D2/6311+G(d,p), Ir:LANL2DZ(f), IEFPCM-MeOH//PBE/6-31G(d), Ir:LANL2DZ. ${ }^{24}$ Values are in $\mathrm{kcal}^{\mathrm{mol}}{ }^{-1}$. Ligand $\mathrm{L3}$ was used for the calculation to minimize conformational isomers; the experimental value was taken from $6 \mathrm{~h}$.

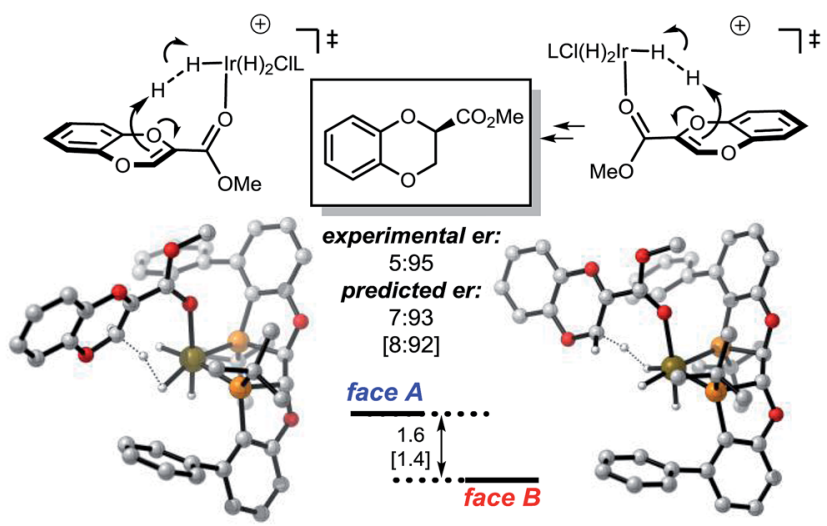

Fig. 5 Energetics of the mode $\mathrm{B}$ protonation of the $\mathrm{CO}_{2} \mathrm{Me}$ substituted benzodioxine. Selectivity-determining conformations are shown. Free energy and enthalpy (in brackets) gaps are calculated using PBE-D2/6-311+G(d,p), Ir:LANL2DZ(f), IEFPCM-MeOH//PBE/6$31 \mathrm{G}(\mathrm{d})$, Ir:LANL2DZ. Values are in $\mathrm{kcal} \mathrm{mol}^{-1}$. Ligand $\mathrm{L3}$ was used for the calculation to minimize conformational isomers; the experimental value was taken from $6 z$.

experimentally obtained result (Fig. 5, computed 7:93 vs. experimental 5:95).

The selectivity basis for the mode B approach is outlined in greater detail in Fig. 7. From the transition state geometry, the structural motif contributing to stabilization is a combination of slipped overlapping $\pi-\pi$ and $\mathrm{sp}^{2} \mathrm{CH}-\pi$ interactions, ${ }^{25}$ which are reported to be relatively strong $\left(\sim 2.5 \mathrm{kcal} \mathrm{mol}^{-1}\right) .{ }^{26}$ In our case, imperfect positioning of the $\mathrm{CH}$ unit relative to the aromatic system $\left(3.13 \AA\right.$ vs. typical $2.73 \AA$ and $136^{\circ}$ vs. $148^{\circ}$ for typical

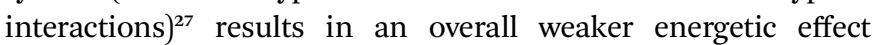
(1.5 kcal mol ${ }^{-1}$ in this case). This interaction is absent in the transition state arising from the other facial approach (face $\mathrm{A}$ in Fig. 5). Even though this electronic interaction is not optimal, the resultant stabilization is sufficient to drive the differentiation of these diastereomeric transition states leading to high selectivity.

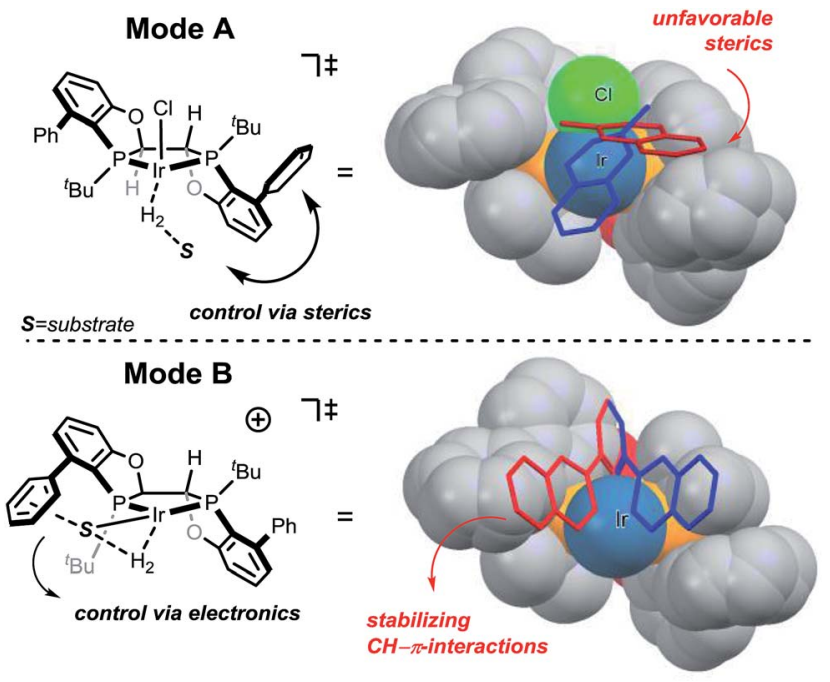

Fig. 6 Stereochemical models for mode A and mode B protonations. Substrate approaches for face A and face B attacks are shown in blue and red respectively.

In summary, we report the discovery of a highly enantioselective ( $>99: 1 \mathrm{er})$ and versatile IrCl/BIDIME-dimer catalyst system for asymmetric hydrogenation reactions to prepare a wide range of chiral 1,4-benzodioxanes including those with alkyl, aryl, heteroaryl, and carbonyl groups at the 2-position. The route commences with a key RCM step to construct the ring of the requisite 1,4-benzodioxines with ppm level catalyst loadings using the nitro-Grela catalyst. Overall, this route represents a general and atom-economical catalytic approach to construct synthetically challenging chiral benzodioxanes. Computational studies suggest that enantioselectivity of the hydrogenation process is controlled by an outer sphere protonation step. Depending on the nature of the substrate, however, coordination to the metal center can intervene creating an inner sphere approach in the corresponding transition states. This specific coordination is a powerful way of altering the spatial orientation of the substrate during the protonation, providing the means to affect the absolute and relative stereochemical outcome of the reaction.

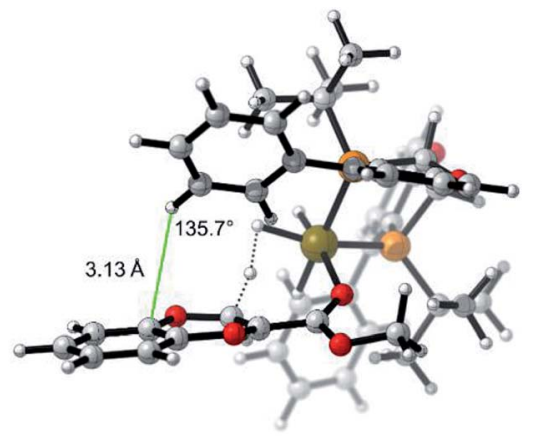

Fig. 7 Model of lowest energy mode B protonation for the 2methoxycarbonyl-1,4-benzodioxine showing electronic stabilizing interactions $\left(\pi-\pi\right.$ and $\mathrm{sp}^{2} \mathrm{CH}-\pi$ interactions). ${ }^{25}$ 


\section{Conflicts of interest}

The authors declare no conflict of interest.

\section{Acknowledgements}

We thank the NIH (GM087605 M. C. K.) and Boehringer Ingelheim Pharmaceuticals for financial support. Computational support was provided by XSEDE (TG-CHE120052). We also thank Dr. Fenghe Qiu, Scott Pennino and Keith McKellop for HRMS analyses and Dr. Dongyue Xin for structural confirmation of 6ae.

\section{Notes and references}

1 (a) L. I. Pilkington and D. Barker, Nat. Prod. Rep., 2015, 32, 1369; (b) A. Abeywardane; M. J. Burke; T. M. Kirrane; M. R. Netherton; A. K. Padyana; L. L. Smith Keenan; H. Takahashi; M. R. Turner; Q. Zhang; Q. Zhang, Benzodioxane Inhibitors of Leukotrien Production, International Patent WO 2012125598 A1, September 9, 2012; (c) R. Zhou, G. Luo and A. G. Ewing, J. Neurosci., 1994, 14, 2402; (d) A. Arnoldi, A. Bassoli, L. Merlini and E. Ragg, J. Chem. Soc., Perkin Trans. 1, 1993, 1359; (e) H. Hikino, Y. Kiso, H. Wagner and M. Fiebig, Planta Med., 1984, 50, 248; (f) L.-G. Zhuang, O. Seligmann, K. Jurcic and H. Wagner, Planta Med., 1982, 45, 172.

2 S. D. Patel, W. M. Habeski, H. Min, J. S. Zhang, R. Roof, B. Snyder, G. Bora, B. Campbell, C. Li, D. Hidayetoglu, D. S. Johnson, A. Chaudhry, M. E. Charlton and N. M. Kablaoui, Bioorg. Med. Chem. Lett., 2008, 18, 5689.

3 T. Tomiyama, S. Wakabayashi and M. Yokota, J. Med. Chem., 1989, 32, 1988.

4 R. Ertan and H. Göker, FABAD J. Pharm. Sci., 1987, 12, 152.

5 M. F. Hibert, M. W. Gittos, D. N. Middlemiss, A. K. Mir and J. R. Fozard, J. Med. Chem., 1988, 31, 1087.

6 A. K. Mir, M. Hilbert, M. D. Trickleband, D. N. Middlemiss, E. J. Kidd and J. R. Fozard, Eur. J. Pharmacol., 1988, 149, 107. 7 G. Vogel, W. Trost, R. Braatz, K. P. Odenthal, G. Brusewitz, H. Antweiler and R. Seeger, Arzneim.-Forsch., 1975, 25, 179. 8 (a) A. Rouf, M. A. Aga, B. Kumar and S. C. Taneja, Tetrahedron Lett., 2013, 54, 6420; (b) S. I. Kuwabe, K. E. Torraca and S. L. Buchwald, J. Am. Chem. Soc., 2001, 123, 12202; (c) E. Valoti, M. Pallavicini, L. Villa and D. Pezzetta, J. Org. Chem., 2001, 66, 1018; (d) W. L. Nelson and J. E. Wennerstrom, J. Chem. Soc., Chem. Commun., 1976, 921. 9 (a) A. Rouf, P. Gupta, M. A. Aga, B. Kumar, A. Chaubey, R. Parshad and S. C. Taneja, Tetrahedron: Asymmetry, 2012, 23, 1615; (b) S. M. Kasture, R. Varma, U. K. Kalkote, S. Nene and B. D. Kulkarni, Biochem. Eng. J., 2005, 27, 66; (c) T. Sakai, K. Hayashi, F. Yano, M. Takami, M. Ino, T. Korenaga and T. Ema, Bull. Chem. Soc. Jpn., 2003, 76, 1441; (d) S. Antus, A. Gottsegen, J. Kajtar, T. Kovacs, T. S. Toth and H. Wagner, Tetrahedron: Asymmetry, 1993, 4, 339.
10 (a) J. Shi, T. Wang, Y. Huang, X. Zhang, Y. Wu and Q. Cai, Org. Lett., 2015, 17, 840; (b) W. Yang, J. Yan, Y. Long, S. Zhang, J. Liu, Y. Zeng and Q. Cai, Org. Lett., 2013, 15, 6022.

11 N. Hu, K. Li, Z. Wang and W. Tang, Angew. Chem., Int. Ed., 2016, 55, 5044.

12 Y. Wang, J. Xia, G. Yang and W. Zhang, Tetrahedron, 2018, 74, 477.

13 X. Yin, Y. Huang, Z. Chen, Y. Hu, L. Tao, Q. Zhao, X.-Q. Dong and X. Zhang, Org. Lett., 2018, 20, 4173.

14 A. K. Chatterjee, J. P. Morgan, M. Scholl and R. H. Grubbs, J. Am. Chem. Soc., 2000, 122, 3783.

15 G. L. Morgans, E. L. Ngidi, L. G. Madeley, S. D. Khanye, J. P. Michael, C. B. de Koning and W. A. L. van Otterlo, Tetrahedron, 2009, 65, 10650.

16 See the ESI. $\dagger$

17 (a) B. Hans-Ulrich, Adv. Synth. Catal., 2002, 344, 17; (b) K. Makino, Y. Hiroki and Y. Hamada, J. Am. Chem. Soc., 2005, 127, 5784.

18 Solvent mixture of MeOH:THF (1:1) was selected for all the substrates for solubility enhancement. AcOH was applied at 30-40 equiv to the starting material for increased catalyst activity. For substrate 5a, a methoxy incorporation impurity was generated when the reaction was run in the absence of $\mathrm{AcOH}$, see the ESI $\dagger$ for details.

19 (a) G. Liu, X. Liu, Z. Cai, G. Jiao, G. Xu and W. Tang, Angew. Chem., Int. Ed., 2013, 52, 4235; (b) R. S. Luo, K. Li, Y. Hu and W. Tang, Adv. Synth. Catal., 2013, 355, 1297; (c) W. Tang, B. Qu, A. G. Capacci, S. Rodriguez, X. Wei, N. Haddad, B. Narayanan, S. Ma, N. Grinberg, N. K. Yee, D. Krishnamurthy and C. H. Senanayake, Org. Lett., 2010, 12, 176.

20 B. Qu, L. P. Samankumara, S. Ma, K. R. Fandrick, J.-N. Desrosiers, S. Rodriguez, Z. Li, N. Haddad, Z. S. Han, K. McKellop, S. Pennino, N. Grinberg, N. C. Gonnella, J. J. Song and C. H. Senanayake, Angew. Chem., Int. Ed., 2014, 53, 14428.

21 During preparation of this manuscript, hydrogenation of the similar substrates was described by Zhang's group using rhodium catalysis: see ref. 13.

22 (a) B. Qu, H. P. R. Mangunuru, S. Tcyrulnikov, D. Rivalti, O. V. Zatolochnaya, D. Kurouski, S. Radomkit, S. Biswas, S. Karyakarte, K. R. Fandrick, J. D. Sieber, S. Rodriguez, J.-N. Desrosiers, N. Haddad, K. McKellop, S. Pennino, H. Lee, N. K. Yee, J. J. Song, M. C. Kozlowski and C. H. Senanayake, Org. Lett., 2018, 20, 1333; (b) X. Wei, B. Qu, X. Zeng, J. Savoie, K. R. Fandrick, J.-N. Desrosiers, S. Tcyrulnikov, M. A. Marsini, F. G. Buono, Z. Li, B.-S. Yang, W. Tang, N. Haddad, O. Gutierrez, J. Wang, H. Lee, S. Ma, S. Campbell, J. C. Lorenz, M. Eckhardt, F. Himmelsbach, S. Peters, N. D. Patel, Z. Tan, N. K. Yee, J. J. Song, F. Roschangar, M. C. Kozlowski and C. H. Senanayake, J. Am. Chem. Soc., 2016, 138, 15473; (c) H. Zhou, Z. Li, Z. Wang, T. Wang, L. Xu, Y. He, Q.-H. Fan, J. Pan, L. Gu and A. S. C. Chan, Angew. Chem., Int. Ed., 2008, 47, 8464; (d) K. H. Hopmann and A. Bayer, Organometallics, 2011, 30, 2483. 
23 (a) M.-L. Li, S. Yang, X.-C. Su, H.-L. Wu, L.-L. Yang, S.-F. Zhu and Q.-L. Zhou, J. Am. Chem. Soc., 2017, 139, 541; (b) G. E. Dobereiner, A. Nova, N. D. Schley, N. Hazari, S. J. Miller, O. Eisenstein and R. H. Crabtree, J. Am. Chem. Soc., 2011, 133, 7547.

24 K. H. Hopmann, Organometallics, 2016, 35, 3795.
25 S. Tsuzuki, K. Honda, T. Uchimaru, M. Mikami and K. Tanabe, J. Am. Chem. Soc., 2002, 124, 104.

26 H. Sun, U. K. Tottempudi, J. D. Mottishaw, P. N. Basa, A. Putta and A. G. Sykes, Cryst. Growth Des., 2012, 12, 5655. 27 M. Nishio, Phys. Chem. Chem. Phys., 2011, 13, 13873. 